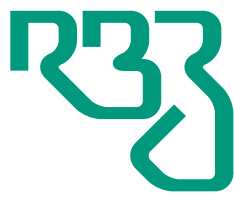

Brazilian Journal of Animal Science ISSN 1806-9290

www.rbz.org.br

\section{Post-hatch fasting and infectious bronchitis vaccination affect growth, gastrointestinal development, and morphometric parameters of the small intestine of broiler breeders up to three weeks of age}

\author{
Miguel Frederico Fernandez-Alarcon ${ }^{1^{*}}$ (iD), Fernando Augusto de Souza ${ }^{1}$, \\ Daniel Mendes Borges Campos ${ }^{1}$, Fabricio Hirota Hada ${ }^{1}$, Wedson Carlos Lima \\ Nogueira $^{2}$, Marcos Macari ${ }^{1}$ (iD, Luiz Roberto Furlan ${ }^{3}$, Renato Luis Furlan ${ }^{1}$ iD \\ ${ }^{1}$ Universidade Estadual Paulista, Departamento de Fisiologia e Morfologia Animal, \\ Jaboticabal, SP, Brasil. \\ ${ }^{2}$ Universidade Federal de Minas Gerais, Instituto de Ciências Agrárias, Montes Claros, MG, Brasil. \\ ${ }^{3}$ Universidade Estadual Paulista, Centro de Aquicultura, Jaboticabal, SP, Brasil.
}

\begin{abstract}
The influence of fasting and vaccination against infectious bronchitis (IB) on growth, gastrointestinal development, and morphometric parameters of the small intestine of newborn broiler breeders was investigated. Weight gain (WG), feed conversion ratio (FCR), gastrointestinal visceral growth, residual yolk sac, and morphometric parameters of the small intestine were measured in chicks aged up to $21 \mathrm{~d}$. We showed that WG was lowest in chicks exposed to longer fasting periods $(72 \mathrm{~h})$, although compensatory gains with increasing age were also observed. Unvaccinated chicks performed better at seven days; however, at $21 \mathrm{~d}$ of age, a compensatory response led to better FCR in vaccinated birds. Allometric growth of the gastrointestinal tract was affected following longer fasting periods, but this effect occurred predominantly in younger birds (three days). Compared with non-fasted, birds fasted for $72 \mathrm{~h}$ had lower villus height and crypt depth along the small intestine at three days and lower villus height in the duodenum and jejunum at seven days. However, at 14 and 21 days of age, the previous changes in intestinal morphology imposed by fasting had been offset. The IB vaccine, applied in the first day of life, does not affect the allometric growth of the gastrointestinal organs, but causes momentary loss in the intestinal morphometry, which contributes to the reduction of WG at seven days. Our results suggest that long fasting periods after hatching ( 48 and $72 \mathrm{~h}$ ) should be avoided in broiler breeders due to the resulting delay in gastrointestinal organ development and growth impairment up to $21 \mathrm{~d}$ of life.
\end{abstract}

Keywords: food restriction, gastrointestinal tract growth, infectious bronchitis immunization, intestinal morphometry

\title{
Introduction
}

Long fasting periods after hatching have been shown to exert a strong influence on the performance of broilers (Sarıca et al., 2014; Sarlak et al., 2017), retarding growth rates and muscle growth (Havely et al., 2003), which may be due to delayed gastrointestinal maturation (Decuypere and Bruggeman, 2007).

In commercial hatcheries that incubate broiler breeder eggs, as well as hatcheries that produce broiler chicks, post-hatch fasting periods can be long. Delayed access to feeding may be even longer for broiler breeders, as their sexing and vaccination procedures are often more complex. In these hatcheries, multi-stage machines are widespread and usually incubate heterogeneous batches of eggs, extending 
hatch windows considerably (Decuypere and Bruggeman, 2007). Besides the time that hatched birds must wait in the hatchery, additional time is spent on selection procedures, dispatch, and transport between the hatchery and the farm. In addition, depending on epidemic threat levels, birds can be vaccinated on arrival at rearing sheds. Taken together, these practices can delay access to feed for up to $72 \mathrm{~h}$ after hatching, as reported in the literature (Willemsen et al., 2010).

Importantly, vaccines also impose an additional energetic cost by triggering an immune response, further affecting the productivity of birds (Cook, 1999; Klasing, 2007). Infectious bronchitis (IB) has resulted in great economic losses to the poultry industry in recent decades, and poultry are often vaccinated against IB on the first day of life (Mondal and Naqi, 2001). In addition to triggering an immune response, the attenuated infectious bronchitis virus (IBV, a coronavirus) may also affect the development of the intestinal mucosa, as the virus has been shown to replicate in the intestinal epithelium (Raj and Jones, 1997; Lobani et al., 2016).

However, little is known about the possible effects of unfavorable nutritional conditions imposed by delayed access to feed and early vaccination during the first days of life of broiler breeders. Although previous studies have addressed the effects of fasting on broilers (Gonzales et al., 2003; Maiorka et al., 2003; Almeida et al., 2006; Sarlak et al., 2017), the effect of fasting on the development of the gastrointestinal tract of broiler breeders may be different, since the former group has a faster growth rate, and hence, higher nutritional requirements in the first weeks of life. Therefore, we evaluated the effects of fasting and vaccination against IB on growth performance, development of gastrointestinal organs, and morphometry of the small intestine of broiler breeders in the first $21 \mathrm{~d}$ of life.

\section{Material and Methods}

This study was approved by the local Committee of Ethics in Animal Use (case no. 014626/18)

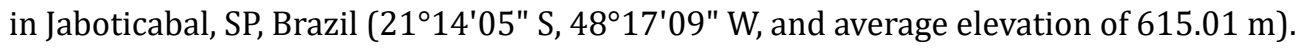

Two thousand eggs from the same grandparent flock $\left(\mathrm{Cobb}^{\circledR}\right)$, with an average weight of $63.69 \mathrm{~g}$, were obtained from a commercial hatchery. The eggs were incubated following standard commercial recommendations $\left(37.5^{\circ} \mathrm{C}\right.$ and $60-65 \%$ relative humidity). The Marek vaccine was administrated at $456 \mathrm{~h}$ of incubation directly into the eggs, which were then transferred to hatchers, with controlled internal temperature $\left(36.5^{\circ} \mathrm{C}\right)$ and relative humidity (70\%). For the experiment, 720 female broiler breeder chicks (sexed by the cloaca) were used, averaging $45 \mathrm{~g}$ and born between 492 and $500 \mathrm{~h}$ of incubation. After selection, the birds were immediately transported to the poultry production sector and housed in two climatic rooms with automated heat-cooling system. Each room contained 20 pens $\left(1.25 \mathrm{~m}^{2} /\right.$ pen) with the temperature adjusted daily, and breeder recommendations were followed to ensure maximum thermal comfort. The light program was set to 23,20 , and $16 \mathrm{~h}$ of light on the first, second, and third week of age, respectively, with a light intensity of 25 lux throughout the experiment.

Seven hundred and twenty Coob broiler breeder chicks were equally distributed in 10 experimental treatments in a $2 \times 5$ factorial design, consisting of five increasing fasting periods after hatching $(0,12,24$, 48 , or $72 \mathrm{~h}$ ), receiving or not the vaccination against IBV. Each treatment consisted of four replications. In this study, only chicks born up to $500 \mathrm{~h}$ of incubation were used and housed in the shed immediately after $510 \mathrm{~h}$ from the start of incubation. Notably, the normal incubation process typically ends after $510 \mathrm{~h}$ of incubation, which, in this study, corresponded to the exact moment the chicks were placed in the shed boxes. Thus, in this paper, the fasting period starting from when the birds were distributed in the experimental units is referred to as the post-hatch period.

For immunization, the birds received the vaccine against chicken IB at housing via the oculo-nasal route (one drop). Each drop of the vaccine contained approximately $1 \times 10^{4} \mathrm{DIE}_{50}$ of the Massachusetts (H-120) live viral strain $\left(\right.$ Biovet $^{\circledR}$ ). Vaccinated and unvaccinated chicks were kept in separate rooms, with daily handling in each room being done by two students (one per room) throughout the experiment.

R. Bras. Zootec., 48:e20180245, 2019 
Following the specific period of fasting applied in each treatment, all chicks were fed ad libitum with the same ration until the end of the experiment. The diet was formulated to meet or exceed the nutritional requirements of broiler breeders according to Rostagno et al. (2011) (Table 1).

Performance was assessed in terms of feed intake (FI), weight gain (WG), and feed conversion ratio (FCR) and was recorded at the end of each week. The FCR was corrected for daily mortality.

One chick per replicate $(\mathrm{N}=4)$ was selected to determine gastrointestinal development parameters (visceral allometric growth, yolk sac allometric ratio, and intestinal length) and for morphometric analysis of the intestinal mucosa at 3, 7,14, and $21 \mathrm{~d}$ of life. The birds were first fasted for $5 \mathrm{~h}$ to empty the intestine and were then stunned and euthanized by cervical dislocation. Gizzard, liver, proventriculus, small intestine (after removal of the chyme), and residual yolk were then removed, weighed, and the intestine measured. Allometric growth of the gizzard, liver, proventriculus, and intestine, as well as the yolk sac allometric ratio, were calculated as proposed by Nir et al. (1993): [(On/Oh) / (BWn/BWh)], in which: $O=$ organ weight, $n=$ day post-hatch, $h=$ weight at hatch, and $B W=$ body weight.

Segments of $3 \mathrm{~cm}$ in length were removed from the duodenum (distal region of the duodenal loop), jejunum (region immediately anterior to Meckel's diverticulum), and ileum (region immediately anterior to the cecal junction), fixed with $10 \%$ formaldehyde at $\mathrm{pH} 7.4$ for $48 \mathrm{~h}$, dehydrated, diaphanized, and embedded in paraffin. Histological slices were prepared according to Torres et al. (2013). Images were obtained with a digital camera attached to a binocular microscope (DM2500 Microscope; DFC280 digital camera - Leica, AOTEC, São Paulo, Brazil) and subsequently analyzed using ImageJ software

Table 1 - Ingredients and nutrient content of experimental diets

\begin{tabular}{|c|c|}
\hline Item & $\begin{array}{c}\text { Initial } \\
\text { (1-21 days) }\end{array}$ \\
\hline \multicolumn{2}{|l|}{ Ingredient (g/kg as fed) } \\
\hline Corn & 652.40 \\
\hline Soybean meal 45\% & 297.40 \\
\hline Soybean Oil & 8.80 \\
\hline Dicalcium phosphate & 18.60 \\
\hline Limestone & 11.20 \\
\hline Sodium chloride & 4.10 \\
\hline Choline chloride $60 \%$ & 0.70 \\
\hline DL-methionine & 1.50 \\
\hline L-lysine & 3.70 \\
\hline Vitamin-mineral premix ${ }^{1}$ & 1.00 \\
\hline Coccidiostat $^{2}$ & 0.50 \\
\hline Total & 1000.00 \\
\hline \multicolumn{2}{|l|}{ Composition } \\
\hline Metabolizable energy (kcal/kg) & 2975 \\
\hline Crude protein (g/kg as fed) & 190.00 \\
\hline Calcium $(\mathrm{g} / \mathrm{kg}$ as fed) & 9.70 \\
\hline Available phosphorus (g/kg as fed) & 4.50 \\
\hline Sodium $(\mathrm{g} / \mathrm{kg}$ as fed) & 1.80 \\
\hline Digestible lysine ( $\mathrm{g} / \mathrm{kg}$ as fed) & 11.80 \\
\hline Digestible methionine ( $\mathrm{g} / \mathrm{kg}$ as fed) & 4.10 \\
\hline Digestible cystine + methionine $(\mathrm{g} / \mathrm{kg}$ as fed $)$ & 6.75 \\
\hline
\end{tabular}

${ }^{1}$ Vitamin-mineral premix provided by Fri-ribe Guaranteed analysis (per kg of premix): vitamin A, 7,000,000 IU; vitamin B1, 1780 mg; vitamin B2, 9600 mg; vitamin B6, 3465 mg; vitamin B7, 1600 mg; vitamin B12, 10,000 mcg; vitamin D3, 3,000,000 IU; vitamin E, 25,000 mg; vitamin K, $980 \mathrm{mg}$; antioxidant, $100 \mathrm{mg}$; iodine, $1300 \mathrm{mg}$; manganese, $76 \mathrm{~g}$; niacin, $34.65 \mathrm{~g}$; copper, $1 \mathrm{~g}$; pantothenic acid, $9500 \mathrm{mg}$; selenium, $273.6 \mathrm{mg}$; zinc, $9.12 \mathrm{~g}$.

${ }^{2}$ Coxistac $12 \%{ }^{\circledR}$ was provided by Phibro Animal Health Corporation. 
(Wayne Rasband, National Institutes of Health, Bethesda, MD). The average of 30 villi and crypt measurements per sample was considered for each intestinal portion.

Data were analyzed as a completely randomized design, and treatments were arranged in a $2 \times 5$ factorial design, with four replicates per treatment. The statistical model included the effects of fasting hours $(0,12,24,48$, or $72 \mathrm{~h}$ ), vaccine (vaccinated vs. unvaccinated), and all interactions at each age, as described below:

$$
\mathrm{Y}_{\mathrm{ijk}}=\mu+\alpha_{\mathrm{i}}+\beta_{\mathrm{j}}+(\alpha \beta)_{\mathrm{ij}}+e_{\mathrm{ijk}}
$$

in which $Y=$ studied parameter, $\mu=$ mean value of the parameter, $\alpha_{i}=$ effect of fasting period after hatching $(0,12,24,48$, or $72 \mathrm{~h}) \mathrm{i}, \beta_{\mathrm{j}}=$ effect of vaccine $\mathrm{j},(\alpha \beta)_{\mathrm{ij}}=$ effect of the interaction between fasting period and vaccination, and $e_{\mathrm{ijk}}=$ residual error.

Data were analyzed using the GLM procedures of SAS (Statistical Analysis System, version 9.2), and means of treatments were compared by Tukey's test $(\mathrm{P}<0.05)$.

\section{Results}

Fasting significantly impaired the performance traits of broiler breeders, depending on the length of feed deprivation (Table 2). At seven days, FI and WG of broiler breeders fasted for $12 \mathrm{~h}$ post-hatch did not differ from birds fed at housing $(0 \mathrm{~h})$. However, at the same age (seven days), FI and WG of birds fasted for 24,48 , and $72 \mathrm{~h}$ post-hatch were significantly and progressively lower than birds fed at housing $(0 \mathrm{~h})(\mathrm{P}<0.05)$. A similar effect was observed at 14 and $21 \mathrm{~d}$ of age for birds fasted for 48 and $72 \mathrm{~h}(\mathrm{P}<0.05)$. Notably, the WG difference between birds fed at housing $(0 \mathrm{~h})$ and those fasted for long periods ( 48 and $72 \mathrm{~h}$ ) was attenuated over time. For example, the weight gain of the 72-h group was $52.0 \%$ of the $0 \mathrm{~h}$ group at seven days, while at 14 and $21 \mathrm{~d}$, this percentage increased to 67.8 and $79.1 \%$, respectively.

Table 2 - Feed intake (FI), weight gain (WG), and feed conversion ratio (FCR) of broiler breeder chicks with different periods of fasting post-hatch and vaccinated or unvaccinated against infectious bronchitis in a 21-day experimental period

\begin{tabular}{|c|c|c|c|c|c|c|c|c|c|}
\hline \multirow[b]{2}{*}{ Day } & \multicolumn{3}{|c|}{ FI } & \multicolumn{3}{|c|}{ WG } & \multicolumn{3}{|c|}{ FCR } \\
\hline & 7 & 14 & 21 & 7 & 14 & 21 & 7 & 14 & 21 \\
\hline
\end{tabular}

Fasting (F)

\begin{tabular}{|c|c|c|c|c|c|c|c|c|c|}
\hline 0 & $171 \mathrm{a}$ & $487 a$ & 1023a & $123 a$ & $342 a$ & $713 a$ & $1.39 \mathrm{ab}$ & 1.42 & 1.44 \\
\hline 12 & $164 a$ & $466 a$ & $1016 a$ & $124 a$ & $341 a$ & $710 a$ & 1.33abc & 1.37 & 1.43 \\
\hline 24 & $149 b$ & $433 a$ & $971 \mathrm{a}$ & $116 b$ & $324 a$ & $686 a$ & $1.29 \mathrm{bc}$ & 1.36 & 1.40 \\
\hline 48 & $113 c$ & $368 b$ & $807 b$ & $91 c$ & $280 \mathrm{~b}$ & $626 b$ & $1.23 \mathrm{c}$ & 1.31 & 1.29 \\
\hline 72 & $92 \mathrm{~d}$ & $323 c$ & $761 b$ & $64 d$ & $232 \mathrm{c}$ & $564 c$ & $1.45 \mathrm{a}$ & 1.39 & 1.35 \\
\hline & \multicolumn{9}{|c|}{ Vaccine $(\mathrm{H}-120)$} \\
\hline \multicolumn{10}{|l|}{ Vaccine (V) } \\
\hline Unvaccinated & 139 & 423 & $967 a$ & $105 a$ & 306 & 666 & 1.31 & 1.38 & $1.45 a$ \\
\hline \multirow[t]{2}{*}{ Vaccinated } & 138 & 411 & $852 b$ & $101 b$ & 303 & 654 & 1.37 & 1.36 & $1.30 \mathrm{~b}$ \\
\hline & \multicolumn{9}{|c|}{ Variation source } \\
\hline $\mathrm{F}$ & $*$ & $*$ & $*$ & $*$ & $*$ & $*$ & $*$ & ns & ns \\
\hline V & ns & ns & $*$ & $*$ & ns & ns & ns & ns & $*$ \\
\hline $\mathrm{F} \times \mathrm{V}$ & ns & ns & ns & ns & ns & ns & ns & ns & ns \\
\hline $\mathrm{CV}$ & 6.06 & 7.42 & 9.32 & 4.53 & 4.27 & 3.31 & 7.98 & 6.79 & 8.95 \\
\hline
\end{tabular}

$\mathrm{CV}$ - coeffficient of variation

a,b - In the columns, means with different letters denote significant differences at $\mathrm{P}<0.05$ by Tukey's test. $* \mathrm{P}<0.05$.

ns - not significant, $\mathrm{P}>0.05$. 
At seven days, the FCR of birds fasted for $48 \mathrm{~h}$ post-hatch was superior to that of birds fed at housing and those fasted for $72 \mathrm{~h}(\mathrm{P}<0.05)$. However, no effect of fasting on FCR in the following weeks $(14$ and 21 d) was observed.

Infectious bronchitis vaccination also resulted in reduced FI and WG in broiler breeders at 21 and seven days $(\mathrm{P}<0.05)$, respectively (Table 2). In addition, at $21 \mathrm{~d}$ of age, the FCR of unvaccinated birds was significantly reduced compared with vaccinated birds $(\mathrm{P}<0.05)$.

At three days of age, the intestine of birds fasted for a few hours post-hatch ( 0 to $12 \mathrm{~h}$ ) was longer than for birds deprived of food for longer periods ( 48 and $72 \mathrm{~h})(\mathrm{P}<0.05)$. At 7,14 , and $21 \mathrm{~d}$, this effect was no longer observed (data not shown).

The residual yolk sac remained visible until three days of age, and the allometric ratio was higher $(\mathrm{P}<0.05)$ for birds fasted for $72 \mathrm{~h}$ than for birds fed immediately after housing $(0 \mathrm{~h})(2.28 \mathrm{vs} 0.95$; data not shown).

The findings demonstrate the detrimental effects of longer fasting periods on gastrointestinal tract growth (Figure 1). The gizzard allometric growth of three-day-old animals was higher in chicks that fasted for $72 \mathrm{~h}$ compared with birds fasted for shorter periods $(\mathrm{P}<0.05)$. At the same age, allometric growth of the proventriculus, liver, and intestine was higher in chicks that received feed from 0 to $24 \mathrm{~h}$ compared with chicks fed later $(48$ and $72 \mathrm{~h})(\mathrm{P}<0.05)$. At the end of the first experimental week, fasting affected only gizzard and proventriculus $(\mathrm{P}<0.05)$, with higher allometric relations associated with longer fasting periods ( 48 and $72 \mathrm{~h}$ ). A similar pattern was observed for the development of the proventriculus in 14-day-old chicks.

At $21 \mathrm{~d}$, the allometric relationship of the liver was higher in birds fasted for $48 \mathrm{~h}$ compared with those fed immediately after housing $(0 \mathrm{~h})(\mathrm{P}<0.05)$. The intestine of birds subjected to the longest fasting period $(72 \mathrm{~h})$ had a higher allometric relation than those fed at housing or one day after $(24 \mathrm{~h})(\mathrm{P}<0.05)$.
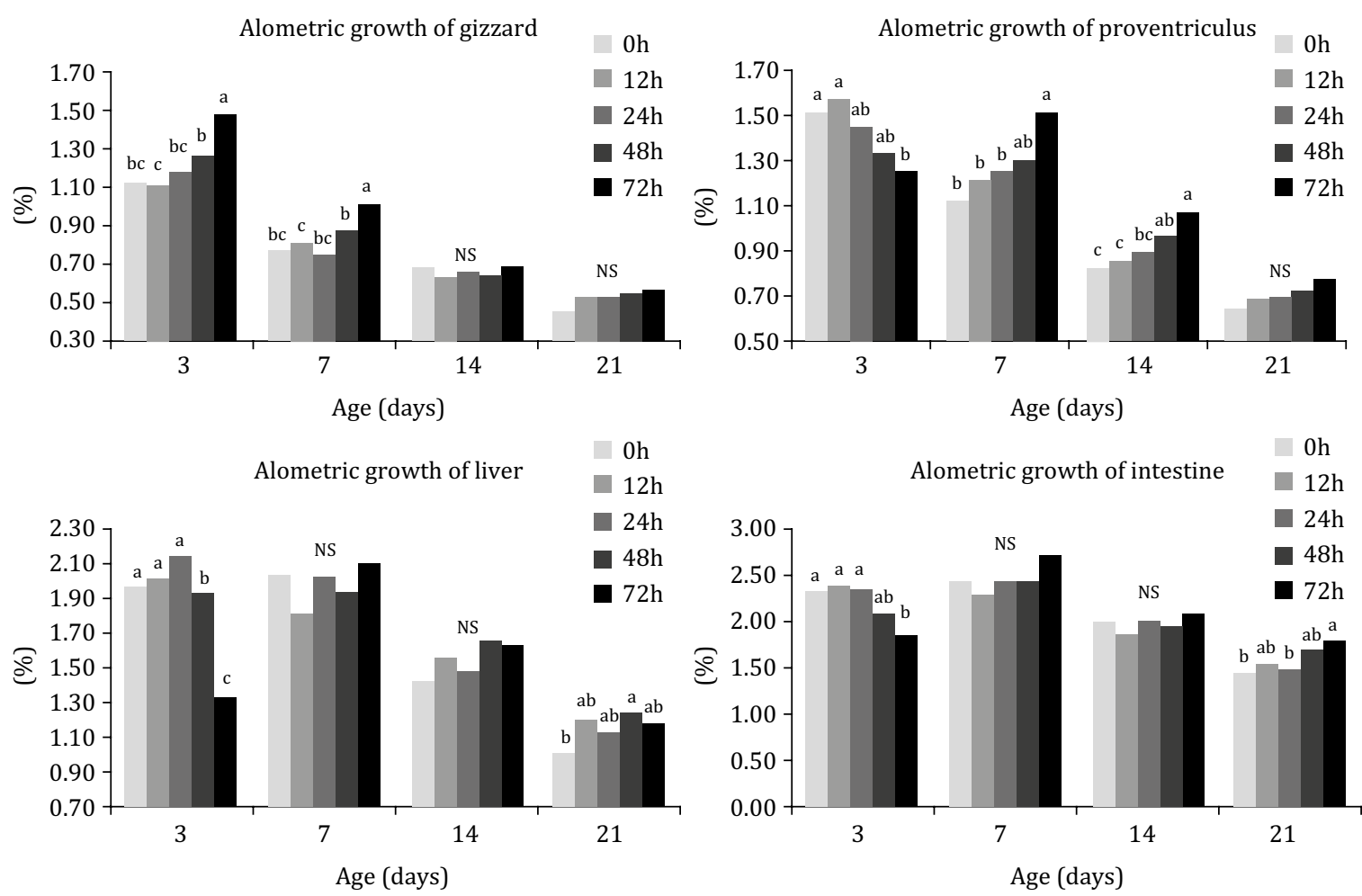

a,b - Different letters denote statistically significant differences at $\mathrm{P}<0.05$ by Tukey's test.

Figure 1 - Allometric growth of gizzard, proventriculus, liver, and intestine of broiler breeders of different ages (days) exposed to different periods of fasting post-hatch. 
The data also show that there were no significant differences between vaccinated and unvaccinated broiler breeders with respect to gastrointestinal tract development up to $21 \mathrm{~d}$ of age (data not shown).

At three days of age, broiler breeder chicks that were still fasting $(72 \mathrm{~h})$ had reduced villus height $(\mathrm{VH})$ and crypt depth (CD) along the small intestine compared with birds fed at housing $(0 \mathrm{~h})(\mathrm{P}<0.05)$, except for CD in the ileum (Table 3). Meanwhile, VH and CD in the duodenum and jejunum of chicks fasted for $48 \mathrm{~h}$ were significantly reduced compared with birds fasted for $12 \mathrm{~h}(\mathrm{P}<0.05)$. At this age,

Table 3 - Effects of post-hatch fasting and IB vaccine on the intestinal morphology in 3, 7, 14, and 21-day-old broiler breeders

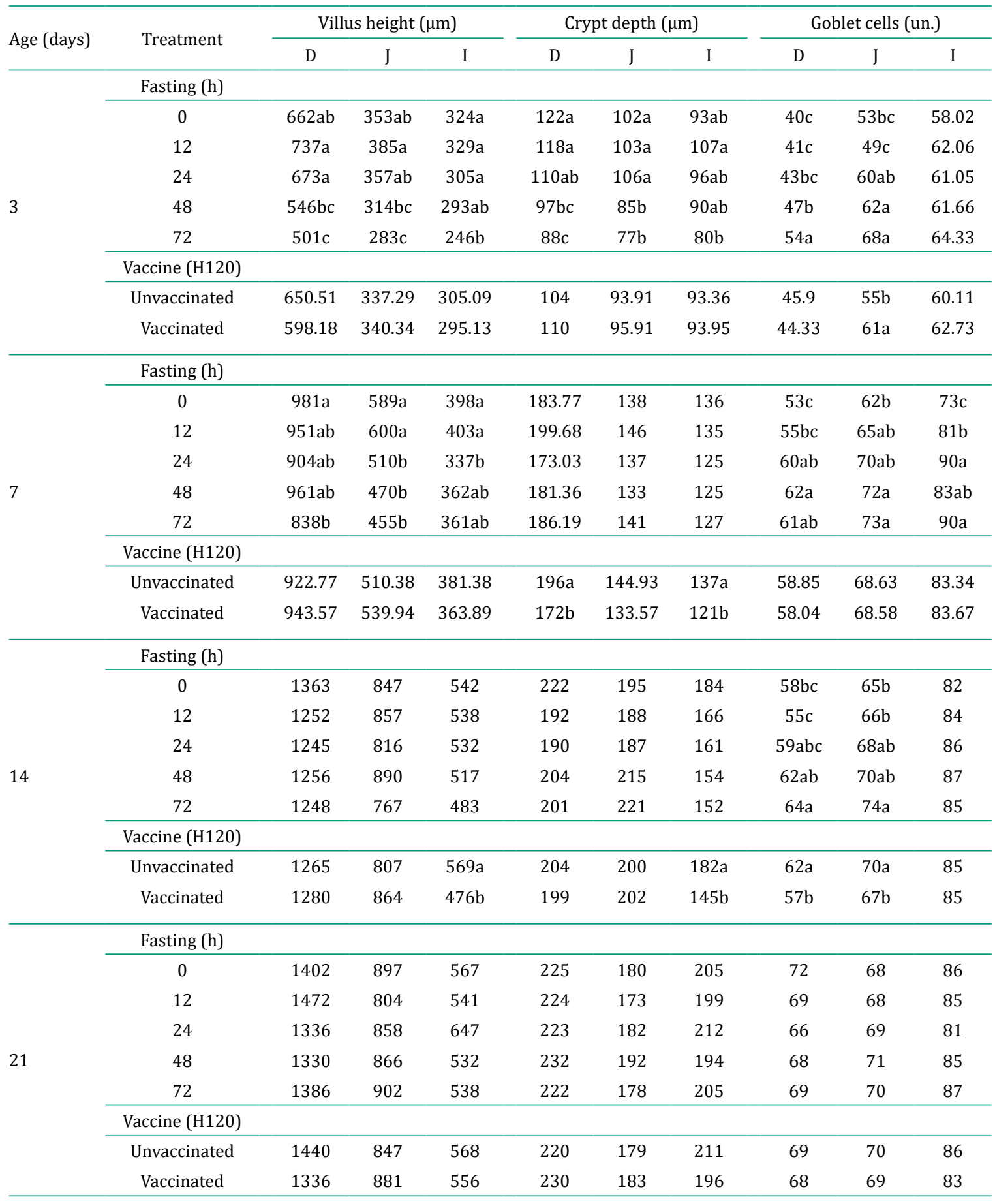

D - duodenum; I- jejunum; I - ileum.

In the columns, means with different letters denote significant differences at $\mathrm{P}<0.005$ by Tukey's test. 
long-term fasted chicks ( 48 and $72 \mathrm{~h}$ ) had greater goblet cell counts (GCC) in both the duodenum and jejunum compared with birds fed shortly after their arrival in the facilities $(0$ and $12 \mathrm{~h})(\mathrm{P}<0.05)$.

At seven days of age, birds fasted for $72 \mathrm{~h}$ presented shorter villi in the duodenum and jejunum than non-fasted birds $(0 \mathrm{~h})(\mathrm{P}<0.05)$. In addition, birds fasted for $72 \mathrm{~h}$ had higher GCC in the duodenum at seven days and in the duodenum and jejunum at $14 \mathrm{~d}$ compared with those fed up to $12 \mathrm{~h}$ post-hatch $(\mathrm{P}<0.05)$. There was no influence of fasting on VH and CD from $14 \mathrm{~d}$, or on GCC at $21 \mathrm{~d}$.

Conversely, vaccination increased GCC in the jejunum of three-day-old birds, and reduced CD in the duodenum and ileum at seven days $(\mathrm{P}<0.05)$. At $14 \mathrm{~d}$, vaccinated birds presented reduced $\mathrm{VH}$ and $\mathrm{CD}$ in the ileum and GCC in the duodenum and jejunum $(\mathrm{P}<0.05)$. At $21 \mathrm{~d}$, vaccination had no effect on the morphometric variables studied.

\section{Discussion}

Post-hatch fasting and vaccination affected performance, gastrointestinal development, and morphometric parameters of the small intestine of broiler breeders up to three weeks of age.

Prolonged fasting periods after hatch ( 48 and $72 \mathrm{~h}$ ) negatively influenced the performance of broiler breeders up to three weeks of age. These results are consistent with studies showing the deleterious effect of fasting on the growth of broiler (Pinchasov and Noy, 1993; Gonzales et al., 2003; Almeida et al., 2006; Sarıca et al., 2014; Sarlak et al., 2017) and turkey (Corless and Sell, 1999; Havely et al., 2003) chicks. Notably, however, although short periods of fasting $(18 \mathrm{~h})$ can impair the performance of 21-day-old broilers (Gonzales et al., 2003), this did not occur with the broiler breeders in this study $(24 \mathrm{~h})$, possibly due to the faster growth curve of broilers compared with broiler breeders.

The attenuation of differences in WG over time between birds fed at housing and those fasted for long periods (48 and $72 \mathrm{~h}$ ) is indicative of compensatory weight gain in this experiment. Compensatory weight gain in response to fasting reportedly occurs, because birds experience a lower energy requirement for maintenance associated with reduced numbers of adipocytes (Noy and Sklan, 1997). In fact, the process of fat production and storage in poultry occurs in a two-stage process (Jones and Farrel, 1992; Jahanpour et al., 2015). At first, the proliferation rate of adipose cells is dominant; later, fat storage becomes more important until day 21 , in which the fat storage rate becomes dominant.

Vaccination also affected the growth performance of broiler breeders in this study. Chicks vaccinated against IB had lower WG and FI than unvaccinated chicks, at seven and $21 \mathrm{~d}$ of age, respectively, consistent with previous research demonstrating a reduction in WG after IB vaccination in broiler chickens (Talebi et al., 2005). The temporary reduction in WG after immunization observed in this study was likely due to activation of the immune system, resulting in reduced appetite and energy available for growth (Van Eerden et al., 2004; Klasing, 2007; Bailly et al., 2016). Nevertheless, WG recovered after the first week of the experiment, showing that the vaccine strain did not elicit a severe infection.

Our results also show that both fasting and vaccination affected the development of the gastrointestinal tract, although in the former case, the effects observed were more pronounced. Specifically, fasting had a negative effect on the allometric growth rates of the proventriculus, gizzard, liver, and growth of the intestine in chicks of all ages up to $21 \mathrm{~d}$ of age. Interestingly, the allometric growth of the gizzard in chicks at three and seven days of age was higher with prolonged fasting periods, which may indicate that exogenous diet is less limiting for growth of the viscera than of liver, proventriculus, and intestine, as observed in a separate study (Pinchasov and Noy, 1993). The residual yolk sac was no longer present after three days of age with all treatment conditions, and the residual rate was higher in birds exposed to longer periods of fasting. Previous research has indicated that this effect may result from impaired gastrointestinal development, reduced metabolism, and body growth induced by fasting (Gonzales et al., 2003; Sarlak et al., 2017). In fact, evidence has shown that yolk sac absorption becomes faster as soon as chicks start receiving food (Sarlak et al., 2017), as the transport of the egg yolk to the intestine can be increased by the resulting increase in intestinal activity.

R. Bras. Zootec., 48:e20180245, 2019 
Severe feed restriction in the first weeks of life of chickens promotes protein catabolism associated with elevated levels of uric acid in plasma, due to the process of gluconeogenesis from amino acids and glycerol in the liver (Jahanpour et al., 2013). This process is regulated by the predominance of the effects of glucagon on insulin in response to fasting (Christensen et al., 2013), which also leads to lipolysis for the production of glycerol for the gluconeogenesis process (Honda et al., 2017). In this study, birds exposed to prolonged fasting ( 48 and $72 \mathrm{~h}$ ) had allometric growth values of the viscera (gizzard, proventriculus, liver and intestine) superior to 1 at three days of life, which probably can be explained by the degradation of body protein and its use as a source of energy for the maintenance of body homeostasis. Protein catabolism seems to affect the carcass in a more pronounced way than the viscera, which makes all sense, considering the preservation of the function of the digestive tract organs, once their size and function play a key role in growth (Jahanpour et al., 2015).

Birds exposed to longer fasting periods showed greater allometric growth of the proventriculus (seven days of age), liver, and intestine ( $21 \mathrm{~d}$ of age). Similarly, birds undergoing an early dietary restriction had liver enlargement after the feed supply had been restored (Ozdogan and Aksit, 2003). An explanation for this effect may be linked to the overeating presented by birds when feeding is restored, which leads to increased organs such as liver and intestine. On the other hand, relative weights of the digestive tract at slaughter of broilers exposed to $75 \%$ food deprivation between 8 and 21 days of life did not differ from the control (Jahanpour et al., 2015). Possibly, the difference found in the literature is related to the time difference between the end of fasting and data collection. Thus, birds subjected to fasting or severe feed restriction in the first stages of life, as soon as they are fed, direct the energy available for the growth of the gastrointestinal organs to allow better utilization of nutrients of the diet.

The other measured factor, vaccination, resulted in increased intestine growth in seven-day-old chicks (data not show), but no effect was observed in older animals. The growth rates of other organs were not affected by the vaccine. These results suggest that even before an immune response is triggered by the vaccine, the development of the intestine and other digestive organs is prioritized. Therefore, the energy demand associated with the immune response does not limit the availability of energy for intestinal development in the first week of life.

We also observed that the morphometric characteristics of the small intestine were affected by longer fasting periods and IB vaccination. Microscopic examination of the small intestine is critical for the evaluation of the functional development of the intestine in chickens, as during the first $14 \mathrm{~d}$ of life, the increase in volume of the intestinal villi may be more important than their length and diameter (Noy and Sklan, 1997). Furthermore, intestinal villus height correlates with the surface area of the intestinal mucosa and, consequently, with the functional capacity of the gut (Tako et al., 2004). Our study demonstrated that long fasting periods intensified the reduction in VH and CD and enhanced GCC throughout the small intestine after three days of life. Similarly, a previous study (Uni et al., 1998) showed that a delay of $36 \mathrm{~h}$ in housing chicks promoted reductions in VH and CD. A different study also showed that a reduction in VH can lead to increased goblet cell density (Geyra et al., 2001). These findings may be related to the reduced proliferation of crypt cells, as fewer cells are available for the growth of the crypt and villi when chicks are exposed to fasting (Geyra et al., 2001). Additionally, 48-h fasting has been shown to affect the development of the ileum less severely than that of the duodenum and jejunum, which was attributed to a slower growth rate of the villi in this segment (Geyra et al., 2001).

Following ad libitum feeding, compensatory responses were observed in the intestinal mucosa during the second and third weeks of rearing. The only exception was with GCC in the duodenum and jejunum at $14 \mathrm{~d}$ in chicks exposed to the longest fasting period $(72 \mathrm{~h})$. The remarkable recovery of the intestinal epithelium after feeding may be related to an improvement in mitotic capacity. Indeed, previous research has shown that one day after fasting was interrupted, most crypt cells of adult rats were stimulated to enter the cell cycle (Hodin et al., 1994), possibly increasing the proliferation and migration of enterocytes from the crypt to the villi. It has also been reported that chicks fasted for $48 \mathrm{~h}$ showed an improvement in the proliferation of crypts and villi, $24 \mathrm{~h}$ after feeding (Geyra et al., 2001). That study showed that chicks fasted for $48 \mathrm{~h}$ had crypt and villus dimensions similar to birds fed at housing, seven 
days after the end of fasting. Therefore, the observed effects of fasting on morphology of the small intestine of broiler breeders in this study were similar to those found in studies with broilers, in which the birds recovered from the initial damage to intestinal morphology after feeding was reestablished. However, broiler chickens have faster growth and visceral development rates (Gonzales et al., 2003), and, therefore, intestinal maturation is more severely affected by longer periods of fasting in broiler chickens than in breeders.

In this study, vaccination promoted a reduction in $C D$ in the duodenum and ileum at seven days of age, and curtailment of $\mathrm{VH}$ and $\mathrm{CD}$ in the ileum at $14 \mathrm{~d}$ of age. Energy expenditure for maintenance of the intestine is high, and normal cell turnover in the epithelium can be affected by reduced nutrient availability (Boleli et al., 2002). The energy expenditure required for the immune response and activation of the inflammatory response associated with the drop in FI may have also limited the energy available for the maintenance of the intestinal epithelium in vaccinated chicks. Conversely, we cannot exclude the fact that the morphological changes we observed in response to the vaccine were related to the putative effect of the attenuated vaccine virus on the gut epithelium. Infectious bronchitis vaccine replication in the cytoplasm of cells of the intestinal epithelium may lead to cell lysis, which can reduce the number of intestinal microvilli (Guy, 1998).

Most changes in intestinal morphology observed in the present study were concentrated in the ileum ( $\mathrm{CD}$ at 7 and $14 \mathrm{~d}$ of age and $\mathrm{VH}$ at $14 \mathrm{~d}$ of age); this was surprising, as when energy availability for intestinal maintenance is low, the segment with the highest turnover, the duodenum (Geyra et al., 2001), is expected to be the most affected. It is known that the ability of IBV to survive in conditions of low $\mathrm{pH}$ and in the presence of bile salts and digestive enzymes may be relevant to their intestinal replication (Raj and Jones, 1997), suggesting that the Massachusetts strain (M41) was sensitive to exposure to $\mathrm{pH} 3$ after just 3 to $4 \mathrm{~h}$ (Cowen and Hitchner, 1975). Although the vaccinal virus isolation in the intestinal epithelium was not done, it is likely that the major morphological changes in the ileum of vaccinated broiler breeders in this study are related to the higher susceptibility of the ileum to IBV replication.

Overall, the changes recorded in the intestinal epithelium of vaccinated birds up to $14 \mathrm{~d}$ of age were not severe. In addition, there was no change in the morphometric parameters analyzed at $21 \mathrm{~d}$ of age. In this study, we used a vaccine strain with low virulence and low tropism for the gastrointestinal tract, which may explain the compensation observed at $21 \mathrm{~d}$ of age compared with the changes observed at $14 \mathrm{~d}$ of age. For example, Ambali and Jones (1991) compared vaccine strains of the Massachusetts 41 (M41) virus with an enterotropic variant (G) and found that both strains had a similar sensitivity to trypsin, although the variant had a 50 -fold higher resistance to sodium tauroglycocholate, which could be related to the increased ability of the variant to replicate in the gut. In our study, the observed reduction in $\mathrm{VH}$ and $\mathrm{CD}$ could be related to the energetic demand associated with the immune response triggered by IBV, although a direct effect of IBV replication on the intestinal epithelium cannot be excluded.

Although this study was not extended to the production period to assess the implications of fasting and vaccine on the production of broiler breeders, our findings may aid in optimizing management practices during the first weeks of life of broiler breeders.

\section{Conclusions}

The vaccine against infectious bronchitis of chickens, applied in the first day of life of broiler breeders, does not affect the allometric growth of the gastrointestinal organs, but causes momentary loss in the intestinal morphometry, which contributes to reduction of weight gain at seven days of life. However, the changes do not compromise the performance of birds from the second week of life.

In addition, the results of the current study suggest that long periods of fasting after hatching ( 48 and $72 \mathrm{~h}$ ) should be avoided in broiler breeders due to the resulting delay in gastrointestinal organ development and growth impairment of the birds until their third week of life.

R. Bras. Zootec., 48:e20180245, 2019 


\section{Acknowledgments}

This work was supported by Fundação de Amparo à Pesquisa do Estado de São Paulo (FAPESP; processes 2008/52524-5 and 2008/54579-1).

\section{References}

Almeida, J. G.; Vieira, S. L.; Gallo, B. B.; Conde, O. R. A. and Olmos, A. R. 2006. Period of incubation and posthatching holding time influence on broiler performance. Brazilian Journal of Poultry Science 8:153-158. https://doi.org/10.1590/S1516-635X2006000300003

Ambali, A. G. and Jones, R. C. 1991. Effects of trypsin and sodium tauroglycocholate on an enterotropic variant of IB virus. Veterinary Record 129:510-511.

Bailly, J.; Scheifler, R.; Belvalette, M.; Garnier, S.; Boissier, E.; Clément-Demange, V.-A.; Gète, M.; Leblond, M.; Pasteur, B.; Piget, Q.; Sage, M. and Faivre, B. 2016. Negative impact of urban habitat on immunity in the great tit Parus major. Oecologia 182:1053-1062. https://doi.org/10.1007/s00442-016-3730-2

Boleli, I. C.; Maiorka, A. and Macari, M. 2002. Estrutura funcional do trato digestório. p.113-120. In: Fisiologia aviária aplicada a frangos de corte. Macari, M.; Furlan, R. L.; Gonzales, E., eds. Funep, Jaboticabal.

Cook, M. E. 1999. Nutritional effects on vaccination. Advances in Veterinary Medicine 41:53-59. https://doi.org/10.1016/ S0065-3519(99)80008-1

Corless, A. B. and Sell, J. L. 1999. The effects of delayed access to feed and water on the physical and functional development on the digestive system of young turkeys. Poultry Science 78:1158-1169. https://doi.org/10.1093/ps/78.8.1158

Cowen, B. S. and Hichtner, S. B. 1975. pH stability studies with avian infectious bronchitis virus (Coronavirus) strains. Journal of Virology 15:430-432.

Christensen, K.; McMurtry, J. P.; Thaxton, Y. V.; Thaxton, J. P.; Corzo, A.; McDaniel, C. and Scanes, C. G. 2013. Metabolic and hormonal responses of growing modern meat-type chickens to fasting. British Poultry Science 54:199-205. https://doi.org/10.1080/00071668.2013.772953

Decuypere, E. and Bruggeman, V. 2007. The endocrine interface of environmental and egg factors affecting chick quality. Poultry Science 86:1037-1042. https://doi.org/10.1093/ps/86.5.1037

Geyra, A.; Uni, Z. and Sklan, D. 2001. The effect of fasting at different ages on growth and the tissue dynamics in the small intestine of young chick. British Journal of Nutrition 86:53-61. https://doi.org/10.1079/BJN2001368

Gonzales, E.; Kondo, N.; Saldanha, E. S.; Loddy, M. M.; Careghi, C. and Decuypere, E. 2003. Performance and physiological parameters of broiler chickens subjected to fasting on the neonatal period. Poultry Science 82:1250-1256. https://doi.org/10.1093/ps/82.8.1250

Guy, J. S. 1998. Virus infections of the gastrointestinal tract in poultry. Poultry Science 77:1166-1175. https://doi.org/10.1093/ps/77.8.1166

Havely, O.; Nadel, Y.; Barak, M.; Rosenboim, I. and Sklan, D. 2003. Early posthatch feeding stimulates satellite cell proliferation and skeletal muscle growth in turkey poults. The Journal of Nutrition 133:1376-1382. https://doi.org/10.1093/jn/133.5.1376

Hodin, R. A.; Graham, J. R.; Meng, S. and Upton, M. P. 1994. Temporal pattern of rat small intestinal gene expression with refeeding. American Journal of Physiology 266:G83-G89. https://doi.org/10.1152/ajpgi.1994.266.1.G83

Honda, K.; Takagi, S.; Kurachi, K.; Sugimoto, H.; Saneyasu, T. and Kamisoyama, H. 2017. Fasting and glucagon stimulate gene expression of pyruvate dehydrogenase kinase 4 in chickens. The Journal of Poultry Science 54:292-295. https://doi.org/10.2141/jpsa.0170004

Jahanpour, H.; Seidavi, A.; Alaw Qotbi, A. A. and Payan-Carreira, R. 2013. Effects of two levels of quantitative feed restriction for a 7-or 14-days period on broilers blood parameters. Acta Scientiae Veterinariae 41:1-11.

Jahanpour, H.; Seidavi, A.; Qotbi, A. A. A.; Van Den Hoven, R.; Rocha e Silva, S.; Laudadio, V. and Tufarelli, V. 2015. Effects of the level and duration of feeding restriction on carcass components of broilers. Archives Animal Breeding 58:99-105. https://doi.org/10.5194/aab-58-99-2015

Jones, G. P. D. and Farrel, D. J. 1992. Early-Life food restriction of chicken. II. Effect of food restriction on the development of fat tissue. British Poultry Science 33:589-601.

Klasing, K. C. 2007. Nutrition and the immune system. British Poultry Science 48:525-537. https://doi. org/10.1080/00071660701671336

Lobani, A. M.; Gharaibeh, S. M. and Al-Majali, A. M. 2016. Relationship between different enteric viral infections and the occurrence of diarrhea in broiler flocks in Jordan. Poultry Science 95:1257-1261. https://doi.org/10.3382/ps/pew054 
Maiorka, A.; Santin, E.; Dahlke, F.; Boleli, I. C.; Furlan, R. L. and Macari, M. 2003. Posthatching water and feed deprivation affect the gastrointestinal tract and intestinal mucosa development of broiler chicks. Journal Applied of Poultry Research 12:483-492. https://doi.org/10.1093/japr/12.4.483

Mondal, S. P. and Naqi, S. A. 2001. Maternal antibody to infectious bronchitis virus: its role in protection against infection and development of active immunity to vaccine. Veterinary Immunology and Immunopathology 79:31-40. https://doi.org/10.1016/S0165-2427(01)00248-3

Nir, I.; Nitsan, Z. and Mahagna, M. 1993. Comparative growth and development of the digestive organs and some enzymes in broiler and egg type chicks after hatching. British Poulttry Science 34:523-532. https://doi.org/10.1080/00071669308417607

Noy, Y. and Sklan, D. 1997. Posthatch development in poultry. Journal Applied of Poultry Research 6:344-354 https://doi.org/10.1093/japr/6.3.344

Ozdogan, M. and Aksit, M. 2003. Effects of feeds containing different fats on carcass and blood parameters of broilers. Journal of Applied Poultry Research 12:251-256. https://doi.org/10.1093/japr/12.3.251

Pinchasov, Y. and Noy, Y. 1993. Comparison of post-hatch holding time and subsequent early performance of broiler chicks and turkey poults. British Poultry Science 34:111-120. https://doi.org/10.1080/00071669308417567

Raj, G. D. and Jones, R. C. 1997. Infectious bronchitis virus: Immunopathogenesis of infection in the chicken. Avian Pathology 26:677-706. https://doi.org/10.1080/03079459708419246

Rostagno, H. S.; Albino, L. F. T.; Donzele, J. L.; Gomes, P. C.; Oliveira, R. F.; Lopes, D. C.; Ferreira, A. S. and Barreto, S. L. T. 2011. Brazilian tables for poultry and swine - Composition of feedstuffs and nutricional requirements. 3rd ed. Animal Science Department UFV, Viçosa, MG, Brazil.

Sarıca, S.; Suiçmez, M.; Çördük, M.; Özdemir, D. and Berberoglu, E. 2014. Effects of oregano essential oil supplementation to diets of broiler chicks with delayed feeding after hatching. Morphological development of small intestine segments. Italian Journal of Animal Science 13:284-289. https://doi.org/10.4081/ijas.2014.3172

Sarlak, S.; Tabeidian, S. A. and Gheisari, A. 2017. Effects of time of initiation of feeding after hatching and diet composition on performance, carcass characteristics, digestive tract development and immune responses of broilers. Animal Production Science 57:1692-1701. https://doi.org/10.1071/AN15839

Tako, E.; Ferket, P. R. and Uni, Z. 2004. Effects of in ovo feeding of carbohydrates and $\beta$-hydroxy- $\beta$-methylbutyrate on the development of chicken intestine. Poultry Science 83:2023-2028. https://doi.org/10.1093/ps/83.12.2023

Talebi, A.; Pourbakhsh, S. A. and Dorostkar, K. 2005. Effects of vaccination routes against IB on performance and immune response of broiler chickens. International Journal of Poultry Science 4:795-798. https://doi.org/10.3923/ ijps.2005.795.798

Torres, K. A. A.; Pizauro Jr., J. M.; Soares, C. P.; Silva, T. G. A.; Nogueira, W. C. L.; Campos, D. M. B.; Furlan, R. L. and Macari, M. 2013. Effects of corn replacement by sorghum in broiler diets on performance and intestinal mucosa integrity. Poultry Science 92:1564-1571. https://doi.org/10.3382/ps.2012-02422

Uni, Z.; Ganot, S. and Sklan, D. 1998. Posthatch development of mucosal function in the broiler small intestine. Poultry Science 77:75-82. https://doi.org/10.1093/ps/77.1.75

Van Eerden, E.; Van Den Brand, H.; Parmentier, H. K.; De Jong, M. C. M. and Kemp, B. 2004. Phenotypic selection for residual feed intake and its effect on humoral immune responses in growing layer hens. Poultry Science 83:1602-1609. https://doi.org/10.1093/ps/83.9.1602

Willemsen, H.; Debonne, M.; Swennen, Q.; Everaert, N.; Careghi, C.; Han, H.; Bruggeman, V.; Tona, K. and Decuypere, E. 2010. Delay in feed access and spread of hatch: importance of early nutrition. World's Poultry Science Journal 66:177-188. https://doi.org/10.1017/S0043933910000243 